\title{
Birth Facility
}

National Cancer Institute

\section{Source}

National Cancer Institute. Birth Facility. NCI Thesaurus. Code C81237.

The facility which provides a setting with provisions for monitoring and delivering babies. 